Helton Rangel Coutinho Junior

\title{
Agentes Comunitários de Habitação: identidade legitimadora ou identidade de projeto?
}

\section{Dissertação de Mestrado}

Dissertação apresentada como requisito parcial para obtenção do grau de Mestre pelo Programa de PósGraduação em Serviço Social do Departamento de Serviço Social da PUC-Rio.

Orientadora: Prof. Denise Pini Rosalem da Fonseca 
Helton Rangel Coutinho Junior

\section{Agentes Comunitários de Habitação: identidade legitimadora ou identidade de projeto?}

Dissertação apresentada como requisito parcial para obtenção do grau de Mestre pelo Programa de Pósgraduação em Serviço Social do Departamento de Serviço Social do Centro de Ciências Sociais da PUC-Rio. Aprovada pela Comissão Examinadora abaixo assinada.

Prof ${ }^{a}$. Denise Pini Rosalem da Fonseca

Orientadora

Departamento de Serviço Social - Puc-Rio

Prof ${ }^{\text {. Lourdes Brazil }}$ Departamento de Economia - UFF

Prof ${ }^{a}$. Sueli Bulhões

Departamento de Serviço Social - Puc-Rio

Prof. Nizar Messari

Vice-Decano de Pós-Graduação do Centro de Ciências Sociais - PUC-Rio

Rio de Janeiro, 17 de Agosto de 2008 
Todos os direitos reservados. É proibida a reprodução total ou parcial do trabalho sem a autorização da universidade, do autor e do orientador.

\section{Helton Rangel Coutinho Junior}

Graduou-se em história na Uni-Rio (Universidade Federal do Estado do Rio de Janeiro) em 2004 e em serviço social na UFRJ (Universidade Federal do Rio de Janeiro) em 2005. Desenvolveu diversos trabalhos na área de serviço social relacionados à educação popular e ao fomento a participação social em políticas e projetos sociais. É o coordenador social do PAC (Programa de Aceleração de Crescimento) do Complexo Manguinhos. Responsável pelo desenvolvimento e implementação do projeto de desenvolvimento social da área citada.

Ficha Catalográfica

Coutinho Junior, Helton Rangel

Agentes comunitários de habitação : identidade legitimadora ou identidade de projeto ? / Helton Rangel Coutinho Junior ; orientadora: Denise Pini Rosalem da Fonseca. -2008.

129 f. : il. (col.) ; $30 \mathrm{~cm}$

Dissertação (Mestrado em Serviço Social)-Pontifícia Universidade Católica do Rio de Janeiro, Rio de Janeiro, 2008. Inclui bibliografia

1. Serviço social - Teses. 2. Agentes comunitários de habitação. 3. Jardom Moriçaba. 4. Favela-Bairro. 5. Favela. 6. Identidade. I. Fonseca, Denise Pini Rosalem da. II. Pontifícia Universidade Católica do Rio de Janeiro. Departamento de Serviço Social. III. Título. 


\section{Agradecimentos}

A toda equipe do CIEDS pelos ensinos referentes ao planejamento dos processos de trabalho, em especial a Nágila Oliveira pelas reflexões e por ter me ensinado a olhar mais para os números, a companheira e assistente social Kalina Honório pela sensibilidade, Estreliane Vidal pelo companheirismo e a Gizele Avena pelo exemplo de comunicabilidade e responsabilidade.

A toda Equipe de Participação Comunitária pelo apontamento de novos horizontes. Em especial aos agentes comunitários Carlos Fidelis, Sandra Nascimento e Genaina Jurema que me acolheram e contribuíram para o entendimento de dinâmicas territoriais.

A todos os profissionais da Secretaria Municipal do Habitat, em especial a colega assistente social Eliete Durante que sempre deu credibilidade e força para o trabalho cotidiano.

A todos meus amigos que sempre me incentivaram na caminhada. Em especial a Alejandra Estevez pelas infindas conversas sobre nossos objetos de estudo e pela visão crítica sobre este nosso mundo. A Patrícia Oliveira pelo afeto de sempre. A Bruna Stamato pelo suporte iconográfico. A Diana Ramos por sua pesquisa jornalística. A Fabiana Bandeira pelo incentivo a organização das idéias. As companheiras Eliane Sousa e a assistente social Jocelene Ignácio pela força e exemplo de vida que encantam. A Daniel Calado por muitas de suas falas e influência criativa. Julio Oliveira pelo exemplar amor a sua terra e a sua gente. 
A professora Denise Fonseca que sempre me incentivou na organização das idéias e me orientou pacientemente na caminhada pela Pontifícia Universidade Católica do Rio de Janeiro.

As professoras Ana Quiroga, Lourdes Brazil e Fátima Gomes que em muito ajudaram nas ponderações sobre meu objeto de pesquisa. Aproveito ainda para agradecer a professora Ana Branco por me estimular a freqüentar mais o campus e na flexibilização de conceitos e técnicas.

A toda equipe do Departamento de Serviço Social da PUC-Rio, principalmente a Marilene e Joana Maria pelo suporte e informações prestadas. Aos funcionários da Biblioteca Central pela presteza no atendimento, especialmente da bibliotecária Marta

Ao CAPES, instituição responsável pelo financiamento da pesquisa sem o qual seria impossibilitada sua realização.

A Deus pela conspiração cósmica e efetiva proteção.

A minha família, mormente minha mãe e seu exemplo de sinceridade, meu pai pela alegria de viver e minha tia Lígia e avós pelo carinho. 


\section{Resumo}

Coutinho Júnior, Helton Rangel; Fonseca, Denise Pini Rosalem da Fonseca (Orientadora). Agentes Comunitários de Habitação: identidade legitimadora ou identidade de projeto? Rio de Janeiro, 2008. 129 p. Dissertação de Mestrado. Departamento de Serviço Social, Pontifícia Universidade Católica do Rio de Janeiro.

Este trabalho tem por objeto o papel político dos Agentes Comunitários da Habitação do programa Favela-bairro da Prefeitura Municipal do Rio de Janeiro. O objetivo deste estudo é descrever e discutir o alcance da ação destes Agentes, enquanto uma nova forma de participação popular, na concepção e implementação de políticas públicas da área da habitação e urbanismo. As categorias utilizadas para a construção do objeto foram: políticas públicas; identidade e território. A pesquisa de campo foi realizada junto aos Agentes Comunitários da Habitação do bairro Jardim Moriçaba, localizado na zona oeste da cidade do Rio de Janeiro, particularmente no setor denominado Senador Vasconcelos. O estudo indicou que a atividade destes Agentes não obteve uma grande legitimidade e representatividade junto à comunidade da qual eles são membros. Por outro lado, o trabalho de campo mostrou que não se pode negar que a atuação destes Agentes represente um passo importante no sentido de garantir uma participação popular mais efetiva na elaboração, gestão e implementação de projetos de urbanização das áreas de favelas.

\section{Palavras-chave}

Agentes comunitários de habitação; Jardim Moriçaba; Favela-bairro; favela; identidade. 


\section{Abstract}

Coutinho Júnior, Helton Rangel; Fonseca, Denise Pini Rosalem da Fonseca (Advisor). Community Agents Housing: egitimadora identity of identity or the the project? Rio de Janeiro, 2008. 129 p. MSc. Dissertation Departamento de Serviço Social, Pontifícia Universidade Católica do Rio de Janeiro.

The subject of this work is the political role of the Community Housing Agents, members of the Favela-bairro Program, Rio de Janeiro City. The goal of this study is to describe and to discuss the limits of these Agents actions, as a new form of popular participation, in the conception and implementation of public policies related to housing and urban planning. The concepts used to build the subject are: public policies; identity and territory. The field work was done with the Community Housing Agents of Jardim Moriçaba, a county located at the west area of the city of Rio de Janeiro, particularly at the Senador Vasconcelos sector. The study indicates that the activity of these Agents did not count on an extended legitimacy and acceptance by the community to where they belong. By the other hand, the field work point out that it is unquestionable that the very existence of those Agents represents a step forward in the process of popular political participation in the conception, management and implementation of urban projects within slum areas.

\section{Keywords}

Community housing agents; Jardim Moriçaba; Favela-bairro; slum; identity. 


\section{Sumário}

1. Introdução

2. Ocupação do solo urbano e participação popular 23

2.1. Território dos sentidos da palavra favela 24

2.2. De Vargas ao final da década de $1970 \quad 27$

2.3. A década de 1980 e o Movimento de Reforma Urbana 34

2.4. A Constituição Federal de 1988

2.5. O contexto atual 41

3. Os agentes comunitários da saúde: uma referência 46

3.1. As propostas da política de saúde 46

3.2. As diferentes respostas do Estado para a saúde 48

3.3. A referência representada pelos agentes comunitários 54 de saúde

58

4. O programa Favela-Bairro e o Agente Comunitário da Habitação

58

$\begin{array}{ll}\text { 4.1. Favela-Bairro: um programa do Rio de Janeiro } & 58 \\ \text { 4.2. O Favela-Bairro sob a ótica do ACH: identidades } & 64\end{array}$ legitimadora e de projeto

4.3. Os Agentes Comunitários da Habitação e a política 80 habitacional carioca

4.4. Uma discussão sobre a identidade do Agente Comunitário da Habitação

5. Jardim Moriçaba 98

5.1. O Favela-bairro 99

5.2. A participação dos moradores 107

5.3. A construção da identidade de projeto 112

6. Considerações Finais 114

$\begin{array}{ll}\text { 7. Referências bibliográficas } & 116\end{array}$

$\begin{array}{lr}\text { 8. Anexos } & 121\end{array}$ 


\section{Lista de siglas e abreviaturas}

\begin{tabular}{|c|c|}
\hline ACS & - Agentes Comunitários da Saúde \\
\hline AIS & - Ações Integradas de Saúde \\
\hline $\begin{array}{l}\text { BEMDOC } \\
\text { BR-EUA }\end{array}$ & $\begin{array}{l}\text { Movimento para o Desenvolvimento e Organização de } \\
\text { Comunidade }\end{array}$ \\
\hline BNH & - Banco Nacional de Habitação \\
\hline CAPs & - Caixas de Aposentadorias e Pensões \\
\hline CHISAMA & $\begin{array}{l}\text { - Coordenadoria de Habitação de Interesse Social da Área } \\
\text { Metropolitana }\end{array}$ \\
\hline CIEDS & $\begin{array}{l}\text { Centro Integrado de Estudos e Programas de } \\
\text { Desenvolvimento Sustentável }\end{array}$ \\
\hline CMP & - Central de Movimentos Populares \\
\hline CODESCO & - Companhia de Desenvolvimento de Comunidade \\
\hline COHAB & - Cooperativa de Habitação Popular \\
\hline CONAM & - Confederação Nacional de Associações de Moradores \\
\hline EPC & $\begin{array}{l}\text { Equipe de Participação Popular inserida no programa } \\
\text { Favela-Bairro }\end{array}$ \\
\hline FNRU & - Fórum Nacional de Reforma Urbana \\
\hline FNSA & - Frente Nacional pelo Saneamento Ambiental \\
\hline IAB & - Instituto de Arquitetos do Brasil \\
\hline IASERJ & $\begin{array}{l}\text { - Instituto de Assistência aos Servidores do Estado do Rio } \\
\text { de Janeiro }\end{array}$ \\
\hline IBAM & - Instituto Brasileiro de Administração Municipal \\
\hline INPS & - Instituto Nacional de Previdência Social \\
\hline INAMPS & $\begin{array}{l}\text { Instituto Nacional de Assistência Médica da Previdência } \\
\text { Social }\end{array}$ \\
\hline FPRU & - Frente Parlamentar pela Reforma Urbana \\
\hline MNLM & - Movimento Nacional de Luta pela Moradia \\
\hline ONG & - Organização Não-Governamental \\
\hline ONU & - Organização das Nações Unidas \\
\hline PACS & - Programa de Agentes Comunitários de Saúde \\
\hline $\begin{array}{l}\text { PEACE } \\
\text { CORPS }\end{array}$ & - Corpos de Paz \\
\hline PNUD & - Programa das Nações Unidas para o Desenvolvimento \\
\hline PROAP & $\begin{array}{l}\text { - Programa de Urbanização e Assentamentos Populares do Rio de } \\
\text { Janeiro }\end{array}$ \\
\hline PSF & - Programa Saúde da Família \\
\hline
\end{tabular}




$\begin{array}{ll}\text { SAGMACS } & \text { - Sociedade de Análises Gráficas e Mecanográficas } \\ \text { SINPAS } & \text { - Sistema Nacional da Previdência Social } \\ \text { SERFHA } & \text { - Serviço Especial de Reabilitação das Favelas e das } \\ \text { SMH } & \text { - Sabitações Insalubres } \\ \text { SUDS } & \text { Secretaria Municipal de Habitação } \\ \text { SUS } & \text { Sistema Unificado e Descentralizado de Saúde } \\ \text { UNMP } & \text { - Sistema Único da Saúde } \\ \text { USAID } & \text { União Nacional por Moradia Popular } \\ & \text { - Anited States Agency for International Development } \\ & \text { Internacional Estados Unidos para o Desenvolvimento }\end{array}$




\section{Lista de figuras}

Figura 1 Gráfico I - Quantidade de relatórios emergenciais

produzidos pela EPC 2005/2006

Figura 2 Gráfico II - Pontos positivos da intervenção sóciourbanística

Figura 3 Gráfico III - Avaliação do Favela-bairro pelos moradores entrevistados

Figura 4 Foto I - Caminho do Velozo, 1999

Figura 5 Foto II - Caminho do Velozo, 2008

105

Figura 6 Foto III - Valão principal, 2004

Figura 7 Foto IV - Valão principal 2007

105

Figura 8 Gráfico IV - Pontos negativos da intervenção sócio106 urbanística

Figura 9 Foto V - Quadra-esportiva Jardim Moriçaba- 2008

Figura 10 Gráfico V - Pontos negativos do trabalho do $\mathrm{ACH}$ 
Figura 11 Gráfico VI - Pontos negativos do trabalho do ACH

113

Figura 12 Gráfico VII - Avaliação do trabalho do ACH

114

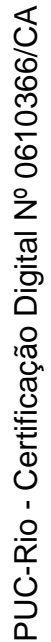

